\title{
Wait times in prostate cancer diagnosis and radiation treatment
}

\author{
Christiaan Stevens, BSc, MSc, MD, FRCPC,; Susan J. Bondy, PhD; \\ D. Andrew Loblaw, BSc, MD, MSc, FRCPC, CIP
}

\section{Abstract}

Introduction: Wait times for cancer diagnosis and treatment are a significant concern for Canadians. Men with prostate cancer experience longer waiting times for diagnosis and treatment than those observed for other cancers. Longer waits are associated with both patient and family psychosocial distress and may be associated with worse prognosis.

Methods: Men referred for treatment of prostate cancer at a single Canadian cancer centre were interviewed. The intervals from suspicion to definitive therapy were calculated, factors associated with delays along this pathway were identified, and common causes of delay identified by patients were described.

Results: A total of 41 consecutive patients participated. The median interval from suspicion to the first fraction of radiotherapy for all patients was 247 days (interquartile range [IQR] 168-367 d). The median diagnostic interval was 53 days (IQR 28-166 d). The median treatment interval was 127 days (IQR 100-180 d). Patients under 70 years old and patients with $<\mathrm{T} 2 \mathrm{c}$ disease had shorter intervals from suspicion to treatment. From diagnosis to start of radiotherapy, patients with low-risk disease had longer intervals. Seventy percent of patients perceived a delay in their care, of which $45 \%, 31 \%$ and $24 \%$ of patients felt the delays were due to the health care system, patient or physician factors, respectively. Interpretation: In this study, $12 \%$ and $0 \%$ of patients met Canadian Strategy for Cancer Control and Canadian Association of Radiation Oncologists wait time recommendations, respectively. A large component of wait time is patient driven. Alternate strategies should be developed and measured to shorten the intervals between the suspicion and treatment of prostate cancer.

\section{Résumé}

Introduction : Les temps $d^{\prime}$ attente pour recevoir un diagnostic de cancer et un traitement constituent une source importante de préoccupation pour les Canadiens. Les hommes atteints de cancer de la prostate attendent encore plus longtemps que les patients atteints d'autres types de cancer pour obtenir un diagnostic et entreprendre un traitement. Ces attentes plus longues se traduisent pour le patient et sa famille par un stress psychosocial et peuvent être liés à un pronostic plus sombre.

Méthodologie : Des hommes aiguillés vers le même centre de cancérologie au Canada pour la prise en charge d'un cancer de la prostate ont été interviewés. L'intervalle entre le soupçon de cancer et le début réel du traitement a été calculé; on a cerné les facteurs liés aux retards le long du processus, et les causes de retards signalées par les patients ont été décrites.

Résultats : Au total, 41 patients consécutifs ont participé. La durée médiane de l'intervalle entre le soupçon de cancer et la première séance de radiothérapie pour tous les patients était de 247 jours (écart interquartile [EIQ], 168 à 367 jours). La durée médiane de l'intervalle avant le diagnostic était de 53 jours (EIQ, 28 à 166 jours). La durée médiane de l'intervalle avant le début du traitement était de 127 jours (EIQ, 100 à 180 jours). Les patients de plus de 70 ans et les patients porteurs d'une tumeur T2c ou moins avancée signalaient des intervalles plus courts entre les premiers soupçons de cancer et le traitement. Entre le diagnostic et le début de la radiothérapie, les patients présentant une maladie à faible risque avaient des intervalles plus longs. Soixante-dix pour cent des patients ont perçu un retard dans leur prise en charge, parmi lesquels $45 \%$ croyaient ce retard lié au système de santé, $31 \%$, à des facteurs liés au patient, et $24 \%$, à des facteurs liés au médecin. Interprétation : Dans cette étude, $12 \%$ et $0 \%$ des patients, respectivement, ont présenté des temps d'attentes conformes aux recommandations de la Stratégie canadienne de lutte contre le cancer et de I'Association canadienne de radio-oncologie. Le temps d'attente est déterminé en grande partie par des facteurs liés au patient. D'autres stratégies devraient être élaborées et évaluées afin de réduire les intervalles entre les premiers soupçons de cancer de la prostate et le début du traitement.

Can Urol Assoc J 2010;4(4):243-8

\section{Introduction}

Wait times for cancer diagnosis and treatment are a significant concern for Canadians. ${ }^{1}$ Cancer is universally seen as a life-threatening disease, and the concern among physicians and patients is that prolonged wait times for diagnosis and treatment may result in cancers being treated at more advanced stages and with worse prognosis. Studies demonstrate that men with prostate cancer experience longer wait times for diagnosis and treatment than those observed for other cancers. ${ }^{2-6}$ While the evidence that longer waits are associated with worse prognosis in prostate cancer is inconclusive, ${ }^{7-16}$ it has been demonstrated that diagnostic and treatment delay are associated with patient and family psychosocial distress in this population. ${ }^{17,18}$

The care pathway for localized prostate cancer is characterized by a sequence of events extending from suspicion 
of disease due to an elevated prostate-specific antigen (PSA) test and/or abnormal examination, to completion of definitive therapy and follow-up or surveillance. Most analyses of wait times for prostate cancer care have lacked data clearly documenting intervals between key time points along the entire care pathway, particularly for care received prior to diagnosis. An understanding of where delays may occur along the pathway and the factors related to delay are essential to effectively prioritize and target wait time reduction interventions in this population.

This study was undertaken to: (1) describe and quantify the intervals within the prostate cancer care pathway from suspicion to definitive therapy for patients referred to and treated with radical radiotherapy (RT) at the Odette Cancer Centre, Toronto, Ontario; (2) identify factors associated with wait times along this pathway; and (3) describe common causes of delay identified by patients.

\section{Methods}

Participants had newly diagnosed localized, biopsy proven adenocarcinoma of the prostate treated with curative intent with external beam RT at the Odette Cancer Centre at Sunnybrook Health Sciences Centre, Toronto, Ontario, Canada, in 2003. Participants were excluded if there was evidence of cognitive deficits that would have precluded reliable recall of the events of interest.

\section{Data collection}

A priori consent was obtained for a semi-structured interview, and access to all medical records, including those of referring and primary care physicians. Participants underwent a Research Ethics Board approved semi-structured interview devised to measure intervals in the prostate cancer care pathway, as well as perceptions of and reasons for delays in the pathway. Reasons for delay were coded into three factors: systemic, patient and physician. Participants were helped with specific memory probes and anchor points. Participants were asked to identify the factor most responsible for delay. For each participant, clinical data (clinical stage, Gleason score,
PSA values) were abstracted retrospectively from the chart.

\section{Definitions: time points and intervals}

Dates of key time points in the process of diagnosis and treatment were recorded. These key time points included the dates of first suspicion of prostate cancer, transrectal ultrasound (TRUS)-guided biopsy, any prostate cancer staging investigations and imaging, dates of referral and initial consultation with urologist and/or radiation oncologist (RO) and first fraction of RT (Fig. 1). The date of suspicion was defined as the date on which a PSA test was $>4.0 \mathrm{ng} / \mathrm{mL}$ or that a PSA test, patient-reported symptom(s) or digital rectal exam resulted in further investigation or referral. The diagnostic interval was defined as the time from the date of suspicion to pathological confirmation of prostate cancer. The treatment interval was defined as the time from the date of diagnosis to the date of the first fraction of RT.

\section{Definitions: delay and type of delay}

To assess patients' perceptions of delay, delay was defined as any interval that was either longer than the patient anticipated or thought to be reasonable. Three types of factors contributing to delay were defined: (1) patient factors, defined as a delay related to an individual not seeking medical attention, or pursuing recommended referrals/ investigations/treatment, in the presence of signs/symptoms that may be related to cancer or a cancer diagnosis; (2) physician factors, defined as a delay related to attaining a consultation with a specialist (urologist, $\mathrm{RO}$ ) or a health care provider (such as a family physician, urologist, RO) not initiating an appropriate diagnostic assessment or treatment in the presence of signs/symptoms that may be related to cancer or a cancer diagnosis; and (3) systemic factors, defined as a delay related to health care system factors that impede an appropriate diagnostic assessment initiated by a physician or referral in the presence of signs/symptoms that may be related to cancer or a cancer diagnosis. Such factors may be unavailability (time or place) of appropriate diagnostic imaging or cytological /pathological expertise and lack of appropriately trained individuals.

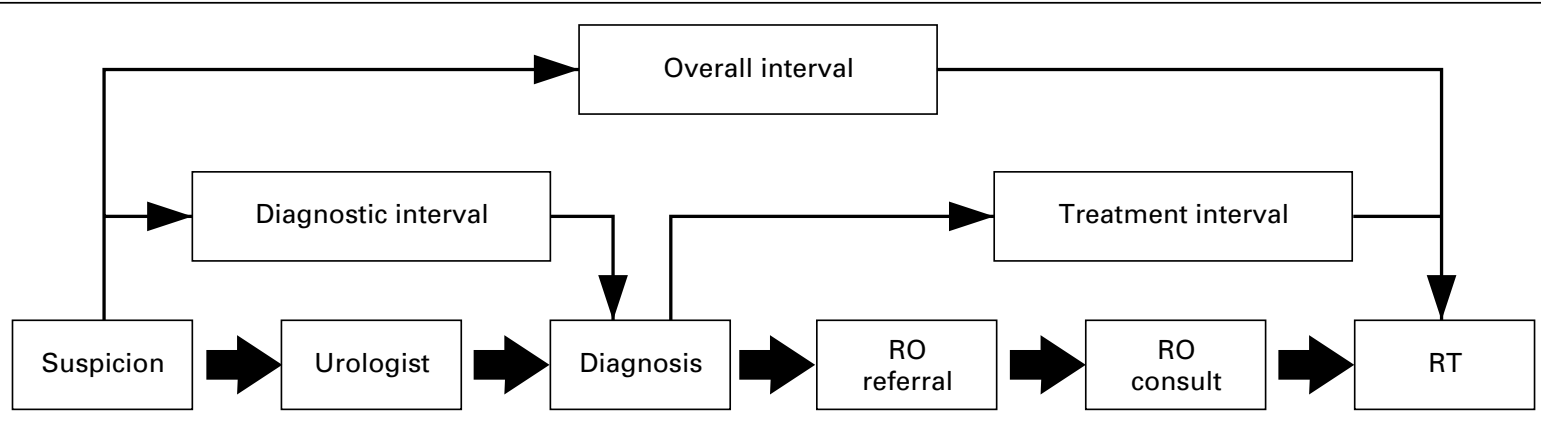

Fig. 1. Timeline of studied intervals. $R 0=$ radiation oncology; $R T=$ radiotherapy. 


\section{Data analysis}

Participants were stratified into low- (PSA $<10$, Gleason score of $\leq 6$, and T-stage $\leq \mathrm{T} 2 \mathrm{a}$ ), intermediate- (PSA 10 to 20, T2b, or a Gleason score $=7$ ) and high-risk (PSA $>20$, Gleason score $\geq$ 8 or higher, or T-stage $\geq T 2$ c) groups based on known predictors of PSA outcome. ${ }^{19}$ Nonparametric data were analyzed using Wilcoxon-Mann-Whitney two sample tests and KruskalWallis one-way analysis of variance. The median was used as the descriptive measure of central tendency, and was used to dichotomize each interval. The level of statistical significance was defined as $p<0.05$. Analysis was performed using SPSS (Version 15.0, SPSS Inc., Chicago, IL).

\section{Results}

\section{Patient characteristics}

The study included 41 patients. Sixty consecutive patients were approached to participate in the study; 10 declined. Of the 50 patients who initially agreed to participate, 9 were excluded because they were receiving adjuvant $(n=4)$ or salvage RT $(n=2)$, or they were unable to meet for the interview $(n=3)$. When risk stratified according to PSA, Gleason score and clinical stage, 8 patients $(19.5 \%)$ had low-risk, 18 (43.9\%) intermediate-risk, and 15 (36.6\%) high-risk prostate cancer, respectively (Table 1 ).

\section{Intervals}

The median interval from suspicion to the first fraction of RT for all patients was 247 days (Fig. 2a). The median diagnostic interval was 53 days. This interval was comprised of two sub-intervals: a sub-interval from suspicion to consultation with an urologist (40 days) and a sub-interval from that consultation to biopsy (26 days) (Fig. 2b). The median treatment interval was 127 days. This interval was comprised of three

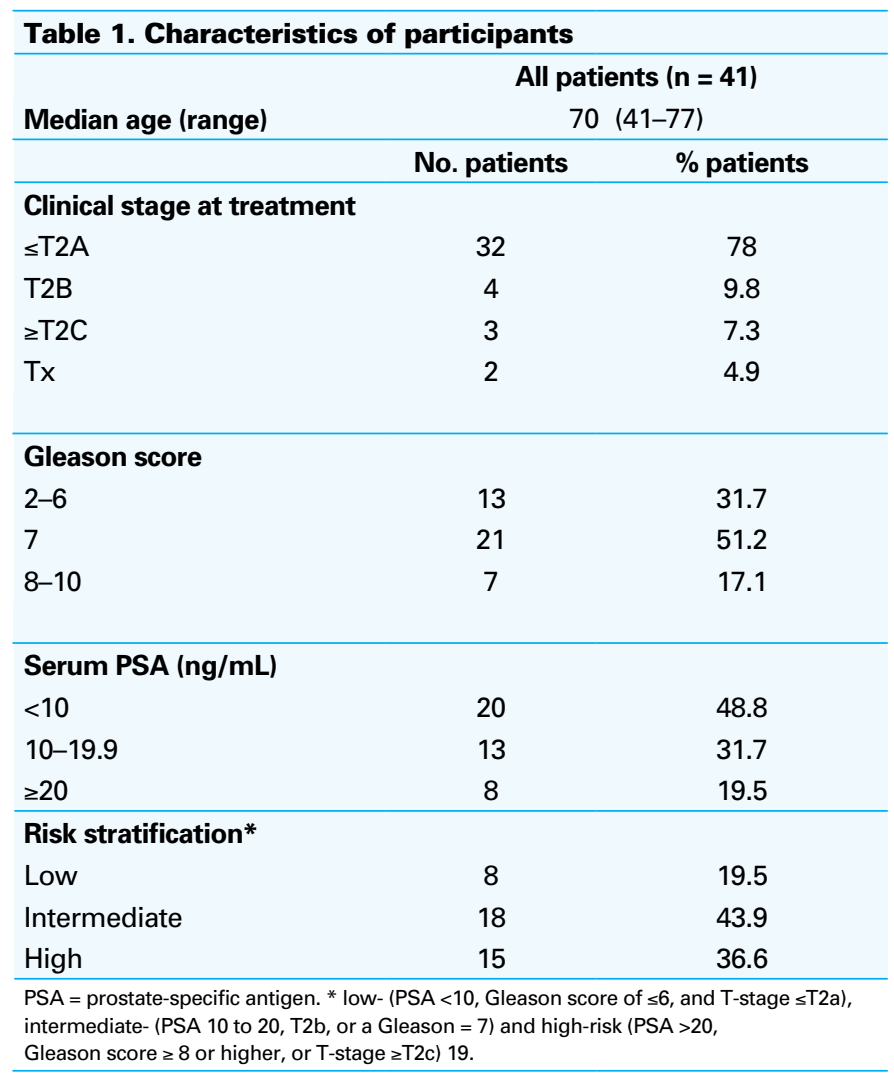

sub-intervals: a sub-interval from biopsy to the request for a referral for RT (41 days), a sub-interval from the request for a referral to a RO and first consultation with a RO (41 days), and lastly a sub-interval from first consultation to first fraction of RT (34 days) (Fig. 2c).

\section{Factors associated with interval length}

Intervals were analyzed by known predictors of PSA outcome and by age (Table 2). From suspicion to first RT fraction, two variables were significantly different: age $(>70$ years vs. $\leq 70$ years: 372 vs. 203 days; $p=0.008$ ) and T

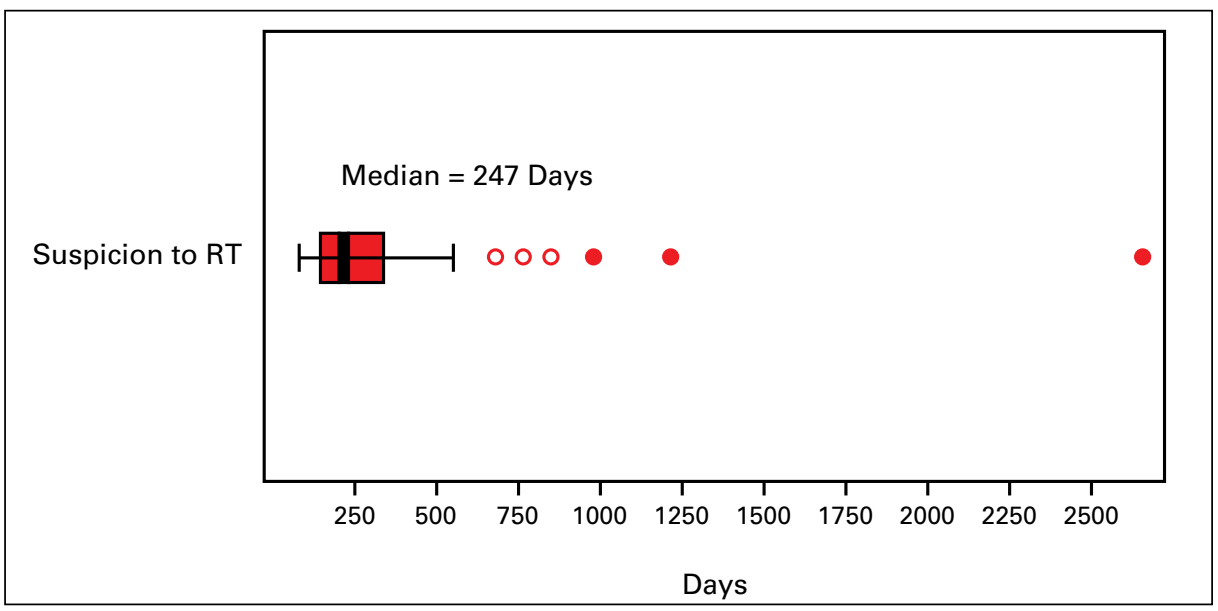

Fig. 2a. The boxes represent values between the 25th and 75th percentiles; the midline marks the median; the projecting lines represent the most extreme values in the data set that were not more than 1.5 times the width of the box beyond either quartile; open circles represent outliers (1.5-3.0 times the interquartile range) and closed circles represent extremes ( $>3.0$ times the interquartile range). This figure illustrates the overall interval from date of suspicion to date of first radiotherapy fraction for prostate cancer treated with radiotherapy $(n=41)$. 


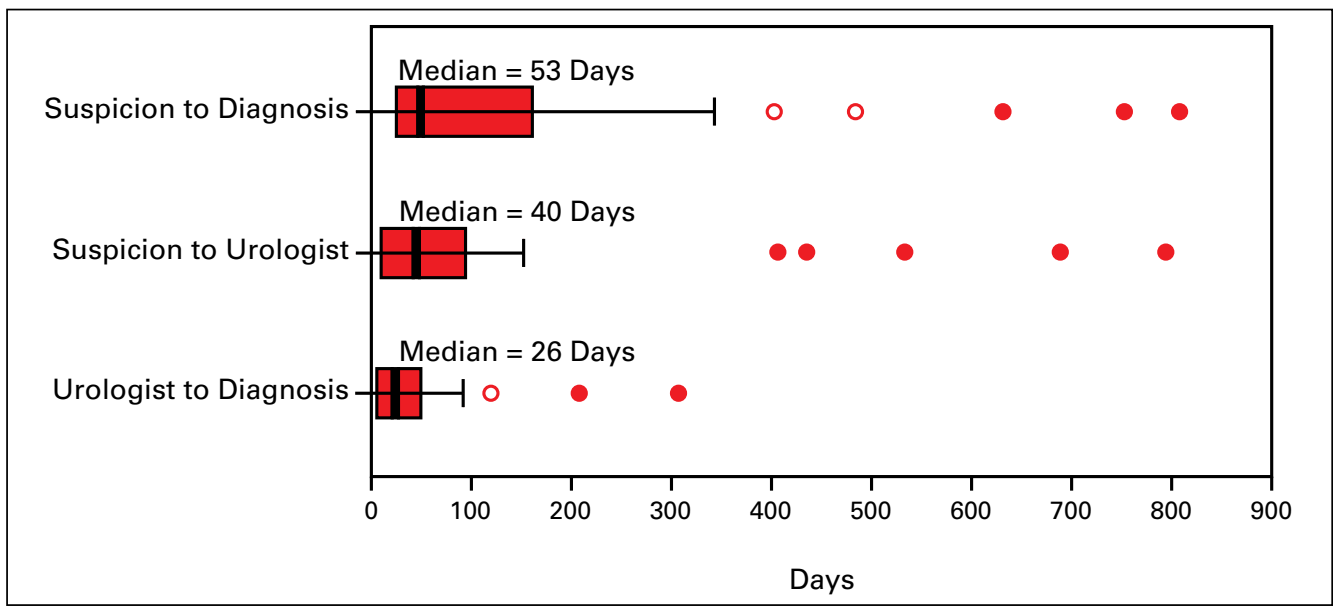

Fig. 2b. The boxes represent values between the 25th and 75th percentiles; the midline marks the median; the projecting lines represent the most extreme values in the data set that were not more than 1.5 times the width of the box beyond either quartile; open circles represent outliers (1.5-3.0 times the Interquartile range) and closed circles represent extremes ( $>3.0$ times the interquartile range). This figure illustrates the diagnostic intervals for patients with prostate cancer treated with radiotherapy $(n=41)$.

category ( $\geq$ T2c vs. $<$ T2c: 168 vs. 304 days; $p=0.034)$. Prostate-specific antigen, Gleason score and risk grouping were not significantly different.

For the interval between suspicion to diagnosis, age, PSA and $T$ category were not statistically significant (although in the interval from suspicion to referral to a urologist, there were longer wait times seen in patients older than 70 years [116 vs. 23 days; $p=0.001]$ ).

From diagnosis to start of RT, intermediate and high-risk patients had shorter wait times compared to low-risk patients (124 vs. 178 days; $p=0.041$ ). Age, PSA, Gleason score and T category were not significantly different. There was a slightly longer interval for high-risk patients between diagnosis and RO referral (54 vs. 28 days; $p=0.044$ ), but 14 of these 15 of these high-risk patients had been started on hormones prior to referral.

\section{Patient identified delay}

Patient identified delay and reasons for delay were then examined in the 41 participants. Of the 41 participants, 29 (70.1\%) perceived that there had been a delay within their prostate cancer care pathway. While many of these patients identified multiple reasons for delay, systemic reasons were most commonly identified as being most responsible for delay $(13 / 29$, $45 \%)$, followed by patient-initiated delay $(9 / 29,31 \%)$, and physician-related delay $(7 / 29,24 \%)$. Patients who perceived a delay in their care pathway did not have longer overall, diagnostic or treatment intervals compared to those who did not perceive a delay in their care pathway (Table 3). There were no differences in the perception of delay between patients in the two groups ( $\leq 70$ and $>70$ years).

\section{Discussion}

In this study, we captured intervals along the entire length of the prostate cancer care pathway in men with localized adenocarcinoma of the prostate referred to and treated with curative RT at the Odette Cancer Centre. We are unaware of any other published studies that have purposefully studied this interval in this population.

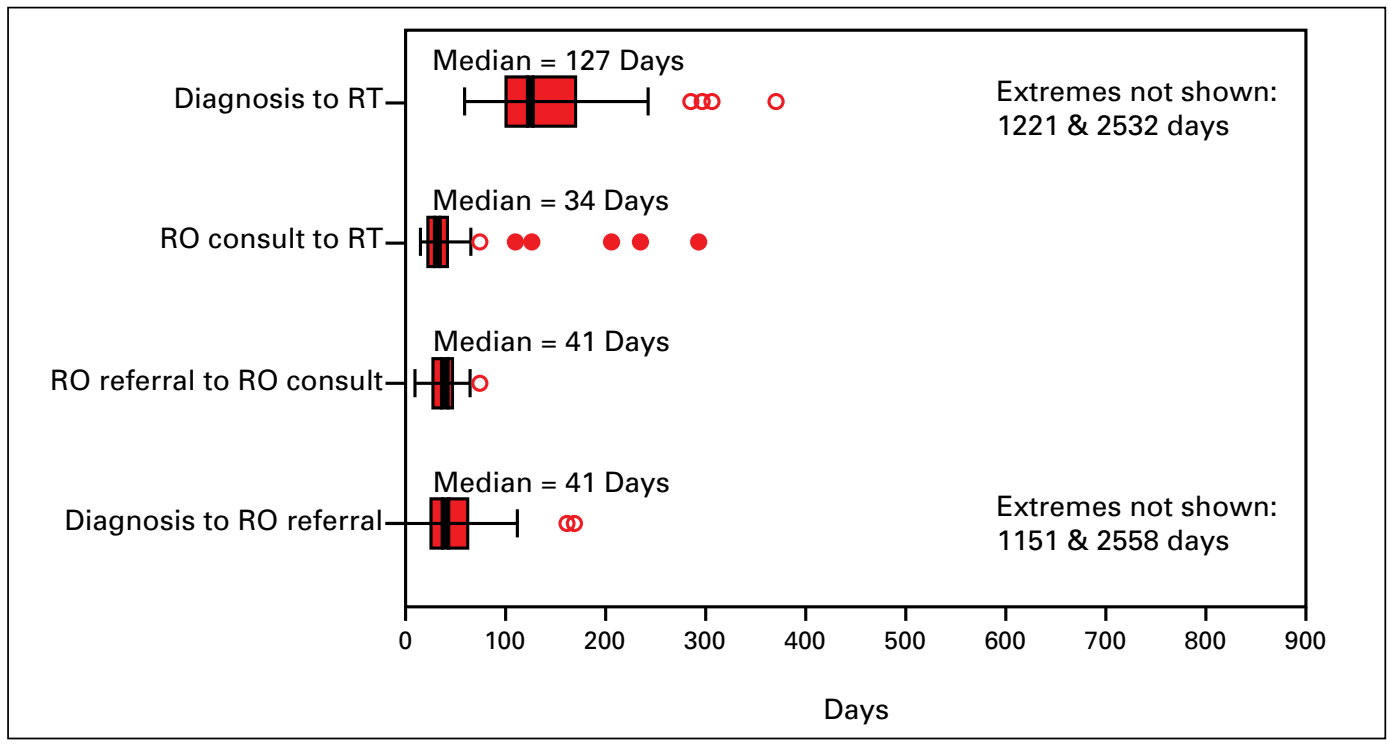

Fig. 2c. The boxes represent values between the 25th and 75th percentiles; the midline marks the median; the projecting lines represent the most extreme values in the data set that were not more than 1.5 times the width of the box beyond either quartile; open circles represent outliers (1.5-3.0 times the interquartile range) and closed circles represent extremes ( $>3.0$ times the interquartile range). This figure illustrates the treatment intervals for 41 patients with prostate cancer treated with radiotherapy. 


\begin{tabular}{|c|c|c|c|c|c|c|c|c|c|}
\hline \multirow[b]{2}{*}{$\mathrm{n}=41$} & \multicolumn{9}{|c|}{ Median interval in days (interquartile range in days) [95\% confidence interval in days] } \\
\hline & & Suspicion & Suspicion & Diagnosis & Suspicion & Urologist & Diagnosis & RO Referral & RO Consult \\
\hline & & $\rightarrow \mathrm{RT}$ & $\rightarrow$ Diagnosis & $\rightarrow \mathrm{RT}$ & $\rightarrow$ Urologist & $\rightarrow$ Diagnosis & $\begin{array}{c}\rightarrow \mathrm{RO} \\
\text { Referral }\end{array}$ & $\begin{array}{c}\rightarrow \mathrm{RO} \\
\text { Consult }\end{array}$ & $\rightarrow \mathrm{RT}$ \\
\hline \multirow[t]{2}{*}{ Overall } & & $\begin{array}{c}247 \\
(168-367)\end{array}$ & $\begin{array}{c}53 \\
(08-166)\end{array}$ & $\begin{array}{c}127 \\
(100-180)\end{array}$ & $\begin{array}{c}40 \\
(11-102)\end{array}$ & 26 & $\begin{array}{c}41 \\
(26-64)\end{array}$ & 41 & 34 \\
\hline & & [172-337] & {$[38-130]$} & [118-162] & [20-71] & [13-43] & [28-55] & [30-45] & [26-39] \\
\hline \multirow{3}{*}{ Age (yrs) } & $\leq 70$ & 203 & 48 & 132 & 23 & 27 & 38 & 38 & 32 \\
\hline & $>70$ & 372 & 164 & 124 & 116 & 25 & 43 & 41 & 39 \\
\hline & & $p=0.008^{*}$ & $p=0.083$ & $p=0.551$ & $p=0.001$ & $p=0.525$ & $p=0.691$ & $p=0.916$ & $p=0.614$ \\
\hline \multirow{3}{*}{ PSA (ng/L) } & $<10$ & 250 & 80 & 128 & 51 & 35 & 35 & 38 & 28 \\
\hline & $\geq 10$ & 244 & 50 & 127 & 30 & 20 & 43 & 41 & 36 \\
\hline & & $p=0.715$ & $p=0.794$ & $p=0.979$ & $p=0.767$ & $p=0.367$ & $p=0.481$ & $p=0.724$ & $p=0.388$ \\
\hline \multirow{3}{*}{$\begin{array}{l}\text { Gleason } \\
\text { score }\end{array}$} & $\leq 6$ & 327 & $\mathrm{~N} / \mathrm{A}$ & 142 & $\mathrm{~N} / \mathrm{A}$ & $\mathrm{N} / \mathrm{A}$ & 34 & 42 & 40 \\
\hline & $>6$ & 237 & & 124 & & & 43 & 39 & 32 \\
\hline & & $p=0.737$ & & $p=0.648$ & & & $p=0.121$ & $p=0.945$ & $p=0.272$ \\
\hline \multirow{3}{*}{$\begin{array}{l}\text { Clinical } \\
\text { stage }\end{array}$} & $<T 2 C$ & 304 & 76 & 140 & 48 & 29 & 36 & 42 & 38 \\
\hline & $\geq \mathrm{T} 2 \mathrm{C}$ & 168 & 43 & 103 & 27 & 9 & 43 & 36 & 25 \\
\hline & & $p=0.034$ & $p=0.480$ & $p=0.108$ & $p=0.289$ & $p=0.858$ & $p=0.593$ & $p=0.858$ & $p=0.028$ \\
\hline \multirow{3}{*}{ Risk group } & Low & 342 & $\mathrm{~N} / \mathrm{A}$ & 178 & $\mathrm{~N} / \mathrm{A}$ & $\mathrm{N} / \mathrm{A}$ & 25 & 38 & 119 \\
\hline & Int + High & 230 & & 124 & & & 43 & 41 & 32 \\
\hline & & $p=0.098$ & & $p=0.041$ & & & $p=0.075$ & $p=0.767$ & $p=0.017$ \\
\hline \multirow{3}{*}{ Risk group } & Low + Int & 275 & N/A & 135 & $\mathrm{~N} / \mathrm{A}$ & N/A & 28 & 39 & 34 \\
\hline & High & 230 & & 124 & & & 54 & 41 & 34 \\
\hline & & $p=0.841$ & & $p=0.862$ & & & $p=0.044$ & $p=0.841$ & $p=0.989$ \\
\hline
\end{tabular}

The overall median interval from suspicion of prostate cancer to RT in our study was 247 days. A study from the United Kingdom, which analyzed intervals from first general practitioner consultation to radical prostatectomy, found a similar overall median interval of 244 days. ${ }^{3}$

Expert groups in North America and Europe have attempted to quantify the maximum length of time that should transpire between certain key events on the cancer care pathway. ${ }^{20-23}$ In general, the median intervals in this study are longer than what most of these guidelines recommend. The Canadian Strategy for Cancer Control has recommended that the time from presentation to a health care professional with signs/symptoms suggestive of cancer to definitive diagnosis should be as short as reasonably achievable, and generally within 4 weeks. ${ }^{22}$ Only 5 of the 41 patients within the study were diagnosed within this time frame.

The Canadian Association of Radiation Oncology (CARO) has established that referral to first consult with a RO should not exceed 10 working days, and that consult to first RT fraction should also not exceed 10 working days. ${ }^{24}$ In this study, no patient was seen and treated at the Odette Cancer Centre within these recommended intervals. These data are consistent with data from population-based studies, which examined median wait times between diagnosis and surgery or RT for prostate cancer, ${ }^{3,4,6,25}$ and a recent survey by CARO in 2006 of the timeliness of RT for prostate cancer in Canada.

Few studies have analyzed factors associated with wait times in prostate cancer treatment. ${ }^{6,25}$ In this study, men $>70$ years and those with less bulky tumours had a significantly longer overall interval from the date of suspicion to date of first RT fraction. The origin of longer wait times for older men seemed to be from the date of suspicion to first consultation with a urologist. However, once patients were assessed by a urologist, their progression along the prostate cancer pathway was no different relative to younger patients.

While the impact of wait times on tumour control in prostate cancer is unresolved, the waiting experience may have other deleterious effects on prostate cancer patients, including anxiety ${ }^{17,18,26}$ and powerlessness ${ }^{27,28}$ (which may be especially stressful in men $\left.{ }^{29}\right)$. In our study, most $(29 ; 70.1 \%)$ of participants perceived a delay in their care pathway. More importantly, over $30 \%$ of the participants identified a patientdriven delay. When reporting wait times (with the purpose of measuring system capacity and responsiveness), we believe it is important to measure/adjust for patient-driven delays.

There are limitations to our study. It was conducted at a single institution in a retrospective nature with a modest sample size over a limited time frame and, therefore, is not a population-based analysis of the prostate cancer care pathway. We did not assess all variables that may have 


\begin{tabular}{lccc}
\hline Table 3. Intervals compared by patient identified delay \\
\hline $\begin{array}{l}\text { Did patient identify } \\
\text { a delay? } \\
\text { (n/41, \% of total) }\end{array}$ & $\begin{array}{c}\text { Median interval in days } \\
\text { Suspicion } \rightarrow \mathrm{RT}\end{array}$ & $\begin{array}{c}\text { Suspicion } \\
\rightarrow \text { Diagnosis }\end{array}$ & Diagnosis $\rightarrow \mathrm{RT}$ \\
\hline NO (12/41, 29.9\%) & 190 & 35 & 142 \\
\hline YES (29/41, 70.1\%) & 253 & 82 & 126 \\
\hline & $p=0.558$ & $p=0.203$ & $p=0.431$ \\
\hline RT = radiotherapy. & & &
\end{tabular}

influenced overall care times, including missed or cancelled appointments. We also acknowledge that missed/cancelled appointments are important contributors to wait times in cancer pathways. On initiation of this study, this factor was not specifically captured. Future studies should be designed to capture these important data.

Despite these limitations, our data provide a more comprehensive picture of the burden of wait times for men along the entire prostate cancer care pathway, a burden not necessarily reflected in the intervals reported by provincial registries. The data demonstrate that at the time of the study, few patients were being diagnosed or treated within recommended wait time guidelines established by expert groups, and that a large component of delay is patient driven.

\section{Conclusion}

Where strategies have been incepted to try to meet these wait time recommendations, the results are encouraging. The Calgary Prostate Institute rapid access clinic, for example, established to reduce the time from referral to biopsy for patients at high risk of prostate cancer, has reduced this interval by $78 \%$, from 95.4 days s $^{30,31}$ to 21 days; this initiative resulted in median wait times from diagnosis to treatment and from referral to treatment of 52 and 101 days, respectively. ${ }^{32}$ Reducing wait times is achievable and alternate strategies should be developed and measured to shorten all intervals between the suspicion and treatment of prostate cancer.

*Fellow, Department of Radiation Oncology, Princess Margaret Hospital, University of Toronto, ON; tUniversity of Toronto Dalla Lana School of Public Health, Toronto, ON; ”Department of Radiation Oncology, Odette Cancer Centre, Sunnybrook Health Sciences Centre, University of Toronto, Toronto, ON

Competing interests: None declared.

This paper has been peer-reviewed.

\section{References}

1. The 10th Annual Health Care in Canada Survey: A national survey of health care providers, managers and the public. 2008 February 13, 2008. hittp://wwww.cha.ca/documents/pa/2007_hcic.pdf. Accessed July 8, 2010.

2. Neal RD, Allgar VL. Sociodemographic factors and delays in the diagnosis of six cancers: analysis of data from the "National Survey of NHS Patients: Cancer." Br J Cancer 2005;92:1971-5.
3. Subramonian KR, Puranik S, Mufti GR. How will the two-weeks-wait rule affect delays in management of urological cancers? J R Soc Med 2003;96:398-9.

4. Mackillop WJ, Fu H, Quirt CF, et al. Waiting for radiotherapy in Ontario. Int I Radiat Oncol Biol Phys 1994;30: 221-8.

5. Simunovic M, Gagliardi A, McCready D, et al. A snapshot of waiting times for cancer surgery provided by surgeons affiliated with regional cancer centres in Ontario. CMAJ 2001;165:421-5.

6. Johnston GM, MacGarvie VL, Elliott D, et al. Radiotherapy wait times for patients with a diagnosis of invasive cancer, 1992-2000. Clin Invest Med 2004;27:142-56.

7. Nam RK, Jewett MA, Krahn MD, et al. Delay in surgical therapy for clinically localized prostate cancer and biochemical recurrence after radical prostatectomy. Can J Urol 2003;10:1891-8.

8. Moul J, Sun L, Amling CL. How long can radical prostatectomy (RP) safely be delayed? CPDR's experience with 3324 cases [abstract]. J Urol 2004;171(Suppl):312.

9. McGowan $D$. The influence of treatment delay in carcinoma of the prostate treated by external beam radiotherapy [abstract]. Clin Invest Med 2000;23:E32.

10. Khan MA, Mangold LA, Epstein Jl, et al. Impact of surgical delay on long-term cancer control for clinically localized prostate cancer. J Urol 2004;172:1835-9.

11. Freedland SJ, Kane CJ, Amling CL, et al. Delay of radical prostatectomy and risk of biochemical progression in men with low risk prostate cancer. J Urol 2006;175:1298-302; discussion 1302-3.

12. Graefen $M$, Walz J, Chun KH, et al. Reasonable delay of surgical treatment in men with localized prostate cancer-impact on prognosis? Eur Urol 2005;47:756-60.

13. Andrews SF, Horwitz EM, Feigenberg SJ, et al. Does a delay in external beam radiation therapy after tissue diagnosis affect outcome for men with prostate carcinoma? Cancer 2005; 104:299-304.

14. Saad F, Finelli A, Dranitsaris $G$, et al. Does prolonging the time to prostate cancer surgery impact long-term cancer control: a systematic review of the literature. Can I Urol 2006;13(Suppl 3):16-24.

15. Boorijian SA, Bianco FJ Jr, Scardino PT, et al. Does the time from biopsy to surgery affect biochemical recurrence after radical prostatectomy? BJU Int 2005;96:773-6.

16. Nguyen PL, Whittington R, Koo S, et al. The impact of a delay in initiating radiation therapy on prostate-specific antigen outcome for patients with clinically localized prostate carcinoma. Cancer 2005;103:2053-9.

17. Dale W, Bilir $P$, Han $M$, et al. The role of anxiety in prostate carcinoma: a structured review of the literature. Cancer 2005; 104:467-78.

18. Gray RE, Fitch MI, Phillips C, et al. Presurgery experiences of prostate cancer patients and their spouses. Cancer Pract 1999;7:130-5.

19. D'Amico AV, Whittington R, Malkowicz SB, et al. Biochemical outcome after radical prostatectomy, external beam radiation therapy, or intersititial radiation therapy for clinically localized prostate cancer. JAMA 1998;280:969-74.

20. Alliance WT. Wait Times Alliance for Timely Access to Health Care; It's About Time. Wait Time Alliance: Ottawa; 2006.

21. Western Canada Waiting List Project, Final Report: Moving Forward. WCWL: Calgary; 2005.

22. Canadian Strategy for Cancer Control: Diagnosis Working Group, Cancer Diagnosis in Canada; Final Recommendations. Canadian Strategy for Cancer Control; 2002.

23. United Kingdom Department of Health: National Health Service. Cancer waiting targets: A guide (version 5); 2006. http://www.dh.gov.uk/en/Publicationsandstatistics/Publications/ PublicationsPolicyAndGuidance/DH_063067. Accessed July 8, 2010.

24. Manpower and Standards of Care in Radiation Oncology Committee. Definition of RT Waiting; 2000. http://www.caro-acro.ca/About_Us/Publications.htm. Accessed July 8, 2010.

25. Siemens DR, Schulze KM, Mackillop WJ, et al. A population-based study of the waiting times for prostatectomy in Ontario. Can J Urol 2005; 12:2568-74.

26. Fitch MI, Gray RE, McGowan T, et al. Travelling for radiation cancer treatment: patient perspectives. Psychooncology 2003;12:664-74.

27. Derrett S, Paul C, Morris JM. Waiting for elective surgery: effects on health-related quality of life. Int J Qual Health Care 1999;11:47-57.

28. Saegrov S, Halding AG. What is it like living with the diagnosis of cancer? Eur J Cancer Care (Engl) 2004;13:145-53.

29. Davison BJ. Degner LF. Empowerment of men newly diagnosed with prostate cancer. Cancer Nurs 1997;20:187-96.

30. Lomas J. New prostate cancer clinic. Vital Signs 2007:4:13

31. Savage C, Hryniuk W. Sleepless in Cancer Land. Cancer Care in Canada, 2006-2007;1:13-6.

32. Kavanagh AG, Lee JC, Donnelly B. Time to treatment of prostate cancer through the Calgary Prostate Institute rapid access clinic. Can J Urol 2008; 15:3975-9.

Correspondence: Dr. D. Andrew Loblaw, Department of Radiation Oncology, Odette Cancer Centre, Sunnybrook Health Sciences Centre, University of Toronto, 2075 Bayview Ave., Toronto, ON M4N 3M5; fax: 416-480-6002 ; andrew.loblaw@sunnybrook.ca 